\title{
Le dopage, le sport et la communauté
}

$\mathrm{L}$ e scandale Ben Johnson il y a près de 20 ans aux Jeux olympiques à Séoul en Corée a attiré l'attention sur la question du dopage. Avons-nous fait des progrès depuis pour régler cet important problème pour la santé publique et le sport?

Un organisme autonome, rebaptisé Centre canadien pour l'éthique dans le sport, a été créé après le scandale pour élaborer un programme national antidopage. Il a servi de modèle à d'autres organismes antidopage nationaux. Néanmoins, 55 athlètes canadiens ont enfreint les règles antidopage depuis 3 ans : 27 ont consommé des drogues «à usage récréatif», et 28 ont absorbé des drogues qui augmentent le rendement.

Les stratégies de dopage semblent souvent anticiper les programmes antidopage. Les tentatives d'identification de taux élevés d'hématocrites stimulés par l'érythropoïétine quelques heures avant la compétition ont incité à dissimuler ce genre de pratique à l'aide de techniques d'hémodilution intraveineuse. La perte de vies catastrophique attribuée à l'érythropoiétine a été remarquée dans de nombreux sports, en particulier le cyclisme que de nombreuses personnes considèrent comme un véritable incubateur de techniques de dopage $\mathrm{e}^{1,2}$.

La capacité de repérer le recours aux stéroïdes anabolisants continue de s'améliorer. Les tests imprévus à l'année ont accentué le dépistage des stéroïdes. Le recours à la testostérone pose toujours des défis. Une élévation soudaine du ratio testostéroneépitestostérone indique habituellement l'usage illégitime de ce stérö̈de anabolisant. On sait que certaines personnes peuvent avoir des ratios naturellement élevés. De plus, on a reconnu récemment que $40 \%$ des porteurs d'un certain génotype découvert chez les deux tiers des gens d'ascendance asiatique peuvent ne pas présenter l'élévation minimale du ratio après l'administration de testostérone ${ }^{3}$.

Il y a d'autres défis à relever. Les programmes antidopage coûtent cher et ils sont de plus en plus complexes et difficiles à gérer. Le fardeau bureaucratique imposé aux athlètes, aux médecins et aux organismes de sport s'alourdit et la viabilité suscite beaucoup de préoccupations. Les athlètes et les organismes de sport sont cependant déterminés à maintenir l'intégrité et à éliminer la tricherie.

Qu'en est-il des athlètes dans la communauté? Étant donné les caractéristiques de la consommation de drogues dans les sports à rendement élevé, on est en droit de se poser des questions sur l'utilisation de stéroïdes anabolisants au terrain de jeu, au gymnase et à l'aréna. On a remarqué il y a plusieurs années une augmentation du recours aux stéroïdes anabolisants dans les sports communautaires ${ }^{4,5}$. Selon un sondage récent, $3,7 \%$ des élèves de $12^{\mathrm{e}}$ année ont affirmé avoir utilisé des stéroïdes ${ }^{6}$. Même s'il est difficile à documenter, il a été postulé que l'usage des stéroïdes est plus fréquent à l'extérieur du sport organisé, dans le milieu de la musculation et autres souscultures où l'on ne cherche pas à contrôler l'utilisation de drogues, ce qui suscite des préoccupations évidentes. Les stéroïdes anabolisants ne sont pas bénins. Leur utilisation est liée à diverses complications endocrinologiques, cardiovasculaires et comportementales.

Pressés de prendre du poids et d'augmenter leur masse musculaire, les athlètes adolescents sont les cibles idéales de ceux qui offrent des approches faciles promettant des résultats étonnants en quelques semaines à peine. Le rendement et la taille sont primordiaux pour certains qui les considèrent comme les clés du succès et de la célébrité. Voilà un défi particulier pour les médecins qui s'intéressent au sport et s'y engagent : nous devons garantir que ces athlètes et, plus important encore, leurs entraîneurs, adoptent des approches du succès dans les sports qui insistent sur l'excellence dans chaque domaine. Les approches pharmacologiques d'amélioration du rendement équivalent à un brouet de sorcière composé de valeurs tordues et de perspectives malveillantes qui posent des risques éventuellement dévastateurs pour la santé.

Les athlètes se retrouvent maintenant aux Jeux olympiques, et certaines performances risquent d'être entachées. En grande majorité cependant, les athlètes se feront concurrence franchement et avec équité. Malheureusement, il peut parfois arriver que leurs réalisations passent inaperçues à cause de la conduite répréhensible d'une minorité. Les athlètes du Canada et d'autres pays sont issus de systèmes sportifs dont les intervenants travaillent sans relâche pour contrer le fléau du dopage.

Les programmes antidopage en milieu olympique soutiennent l'esprit sportif et maintiennent la confiance du public. Il est aussi important de se préoccuper de la consommation de drogues dans les sports communautaires. Les répercussions de ce genre de comportement exigent des interventions réfléchies et stratégiques pour maintenir l'intégrité des sports et la santé publique.

\section{Andrew Pipe MD dip. médecine du sport}

Centre de prévention et de réadaptation Minto

Institut de cardiologie de l'Université d'Ottawa

\section{Paul C. Hébert MD MHSc}

Rédacteur en chef

JAMC

Ottawa (Ont.)

Avec l'équipe de rédaction de l'éditorial (Rajendra Kale MD,

Matthew B. Stanbrook MD PhD, Barbara Sibbald BJ,

Ken Flegel MDCM MSc, Noni MacDonald MD MSc, et Amir Attaran LLB DPhil)

Intérêts concurrents: Aucuns déclarés pour Andrew Pipe. Voir www.cmaj.ca /misc/edboard.shtml pour les déclarations des membres de l'équipe de rédaction de l'éditorial.

Traduit par le Service de traduction de l'AMC.

La version française de l'éditorial a été quelque peu abrégée en raison de contraintes d'espace.

\section{RÉFÉRENCES}

1. Fotheringham W. Inquiry into Belgian cyclists' deaths raises new fears over EPO. The Guardian 2004 Feb 16.

2. Lippi G, Franchini M, Guidi GC. Switch off the light on cycling, switch off the light on doping. Br J Sports Med 2008;42:162.

3. Schulze JJ, Lundmark J, Garle M, et al. Doping test results dependent on genotype of UGT2B17, the major enzyme for testosterone glucurodination. J Clin Endocrinol Metab 2008;93:2500-6.

4. Melia P, Pipe A, Greenberg L. The use of anabolic-androgenic steroids by Canadian students. Clin J Sport Med 1996;6:9-14.

5. Adlaf E, Paglia-Boak A. Drug use among Ontario students 1977-2005. OSDUS highlights. Toronto: Centre for Addiction and Mental Health; 2005.

6. Liu H, Bravata D, Olkin I, et al. Systematic review: the effects of growth hormone on athletic performance. Ann Intern Med 2008;148:747-58. 